\title{
Screening Indoor Plants for Volatile Organic Pollutant Removal Efficiency
}

\author{
Dong Sik Yang \\ Department of Horticulture, University of Georgia, Athens, GA 30602-7273
}

Svoboda V. Pennisi

Department of Horticulture, University of Georgia, Griffin, GA 30223

Ki-Cheol Son

Department of Environmental Science, Konkuk University, Seoul 143-701, Korea

\author{
Stanley J. Kays ${ }^{1}$ \\ The Plant Center, Department of Horticulture, University of Georgia, 1111 \\ Plant Science Building, Athens, GA 30602-7273
}

Additional index words. volatile organic compounds, benzene, toluene, octane, trichloroethylene, $\alpha$-pinene, phytoremediation, indoor air quality

Abstract. Twenty-eight ornamental species commonly used for interior plantscapes were screened for their ability to remove five volatile indoor pollutants: aromatic hydrocarbons (benzene and toluene), aliphatic hydrocarbon (octane), halogenated hydrocarbon [trichloroethylene (TCE)], and terpene ( $\alpha$-pinene). Individual plants were placed in 10.5-L gas-tight glass jars and exposed to $\approx 10 \mathrm{ppm}(31.9,53.7,37.7,46.7$, and $55.7 \mathrm{mg} \cdot \mathrm{m}^{-3}$ ) of benzene, TCE, toluene, octane, and $\alpha$-pinene, respectively. Air samples $(1.0 \mathrm{~mL})$ within the glass containers were analyzed by gas chromatography-mass spectroscopy 3 and $6 \mathrm{~h}$ after exposure to the test pollutants to determine removal efficiency by monitoring the decline in concentration over $6 \mathrm{~h}$ within sealed glass containers. To determine removal by the plant, removal by other means (glass, plant pot, media) was subtracted. The removal efficiency, expressed on a leaf area basis for each volatile organic compound (VOC), varied with plant species. Of the 28 species tested, Hemigraphis alternata, Hedera helix, Hoya carnosa, and Asparagus densiflorus had the highest removal efficiencies for all pollutants; Tradescantia pallida displayed superior removal efficiency for four of the five VOCs (i.e., benzene, toluene, TCE, and $\alpha$-pinene). The five species ranged in their removal efficiency from 26.08 to $44.04 \mu \mathrm{g} \cdot \mathrm{m}^{-3} \cdot \mathrm{m}^{-2} \cdot \mathrm{h}^{-1}$ of the total VOCs. Fittonia argyroneura effectively removed benzene, toluene, and TCE. Ficus benjamina effectively removed octane and $\alpha$-pinene, whereas Polyscias fruticosa effectively removed octane. The variation in removal efficiency among species indicates that for maximum improvement of indoor air quality, multiple species are needed. The number and type of plants should be tailored to the type of VOCs present and their rates of emanation at each specific indoor location.

The importance of indoor air quality to human health has become of increasing interest in developed countries where inhabitants often spend over $90 \%$ of their time indoors (Jenkins et al., 1992; Snyder, 1990). Indoor air has been reported to be as much as 12 times more polluted than that outdoors (Ingrosso, 2002; Orwell et al., 2004; Zabiegała, 2006). Indoor air pollutants primarily originate from building product emissions, human activities inside the building, and infiltration of outdoor air (Wolkoff and Nielsen, 2001; Zabiegała, 2006) and have increased as a result of the lower gas exchange rates of newer, more energy-efficient buildings (Cohen, 1996). Indoor air pollutants include volatile organic compounds (VOCs), particulate mat-

Received for publication 14 Nov. 2008. Accepted for publication 7 Jan. 2009.

${ }^{1}$ To whom reprint requests should be addressed; e-mail kaysstan@uga.edu. ter, ozone, radon, lead, and biological contaminants (Destaillats et al., 2008). Exposure can cause acute illnesses (e.g., asthma, nausea) and chronic diseases (e.g., cancer, immunologic, neurologic, reproductive, developmental, and respiratory disorders) (Suh et al., 2000).

VOCs emanating from paints, varnishes, adhesives, furnishings, clothing, solvents, building materials, combustion appliances, and potable water (Jones, 1999; Maroni et al., 1995; Zabiegała, 2006) have a negative effect on indoor air quality (Darlington et al., 2000). VOCs are generally classified as aromatic hydrocarbons (e.g., benzene, toluene, ethylbenzene, xylene), aliphatic hydrocarbons (e.g., hexane, heptane, octane, decane), halogenated hydrocarbons [e.g., trichloroethylene (TCE), methylene chloride], and terpenes (e.g., $\alpha$-pinene, $d$-limonene) (Jones, 1999; Suh et al., 2000; Wolkoff and Nielsen, 2001; Won et al., 2005; Zabiegała, 2006). Benzene and toluene, octane, TCE, and $\alpha$-pinene are representative VOCs from each class (i.e., aromatic hydrocarbons, aliphatic hydrocarbons, halogenated hydrocarbons, and terpenes, respectively) and are considered to be important indoor air pollutants as a result of their toxicity (Liu et al., 2007; Newman et al., 1997; Orwell et al., 2006).

Plants remove VOCs from indoor air through stomatal uptake, absorption, and adsorption to plant surfaces (Beattie and Seibel, 2007; Korte et al., 2000; Sandhu et al., 2007). Several indoor species have been screened for their ability to remove benzene (Liu et al., 2007), some of which could remove 40 to $88 \mathrm{mg} \cdot \mathrm{m}^{-3} \cdot \mathrm{d}^{-1}$ (Orwell et al., 2004), in addition to other VOCs (e.g., toluene, TCE, $m$-xylene, hexane) (Cornejo et al., 1999; Orwell et al., 2006; Wood et al., 2002; Yoo et al., 2006). The efficiency of VOC removal varies substantially among species (Yoo et al., 2006) and with the molecular characteristics of each compound. To date, only a limited number of indoor species have been tested for their phytoremediation potential and the range of pollutants assessed is even more limited (Cornejo et al., 1999; Ugrekhelidze et al., 1997; Wolverton et al., 1989; Wood et al., 2002). It is evident that a better understanding of the phytoremediation potential of a diverse range of indoor plants is needed. In this study, a cross-section of indoor plants (28 species) was screened for their ability to remove five important VOCs with differing chemistries (benzene, toluene, octane, TCE, and $\alpha$-pinene).

\section{Materials and Methods}

Plant material. Twenty-eight species of popular indoor ornamental plants available in the southeastern United States, which represented 26 genera and 15 botanical families (Table 1), were obtained from commercial sources. After the media was washed from the roots, the plants were repotted in $10-\mathrm{cm}$ (500-cc) pots using a growing media comprised of peatmoss, pine bark, and perlite/ vermiculite $(2: 1: 1, \mathrm{v} / \mathrm{v})$ (Fafard 3B; Fafard, Anderson, SC) and grown in a shade house for 8 weeks before acclimatization for 12 weeks under indoor conditions, $22 \pm 1{ }^{\circ} \mathrm{C}$, $50 \%$ relative humidity, and $5.45 \mu \mathrm{mol} \cdot \mathrm{m}^{-2} \cdot \mathrm{s}^{-1}$ photosynthetically active radiation $(P A R)$ (LI-COR LI-189 light meter with a line quantum sensor; LI-COR, Lincoln, NE). The plants were watered as needed during growth and acclimatization periods. At the end of the experiment, the leaf areas were determined using a LI-3100c leaf area meter (LI-COR) to allow expressing the removal efficiency on a leaf area basis.

Introduction of volatile organic compounds. Plants were placed in 10.5-L gas-tight glass jars (one plant/jar) with the lid fitted with welded stainless steel tubing inlet and outlet ports. To facilitate a uniform distribution of the gases in the jar, the inlet tubing extended downward within the jar following the contour of the side of the jar, three-fourths of the distance to the base. The lids were sealed using specially constructed $11.8 \mathrm{~cm}$ o.d. $\times 9.8 \mathrm{~cm}$ i.d. 
Table 1. Family, Latin binomial, common name, and leaf area of test plants exposed to five representative volatile organic compounds (benzene, toluene, octane, trichloroethylene, and $\alpha$-pinene) over $6 \mathrm{~h}$ during the day.

\begin{tabular}{|c|c|c|c|c|}
\hline No. & Family & Latin binomial & Common name & Leaf area $\left(\mathrm{cm}^{2} /\right.$ plant $)$ \\
\hline 2 & Acanthaceae & Hemigraphis alternata (Burm.f.) T. Anders 'Exotica' & Purple waffle & $352 \pm 37$ \\
\hline 3 & Agavaceae & Dracaena fragrans (L.) Ker-Gawl. & Corn plant & $712 \pm 39$ \\
\hline 4 & Agavaceae & Sansevieria trifasciata Prain & Snake plant & $346 \pm 51$ \\
\hline 6 & Araceae & Anthurium andreanum Linden & Flamingo flower & $616 \pm 76$ \\
\hline 7 & Araceae & Dieffenbachia seguine (Jacq.) Schott ${ }^{\mathrm{z}}$ & Dumb cane & $670 \pm 52$ \\
\hline 8 & Araceae & Philodendron scandens ssp. oxycardium & Heart leaf philodendron & $1085 \pm 28$ \\
\hline 12 & Araliaceae & Schefflera arboricola (Hayata) Merr. 'Variegata' & Variegated schefflera & $587 \pm 56$ \\
\hline 13 & Araliaceae & Schefflera elegantissima (Hort. Veitch ex Mast.) Lowry \& Frodin ${ }^{\mathrm{x}}$ & False aralia & $372 \pm 68$ \\
\hline 14 & Araliaceae & Hedera helix $\mathrm{L}$. & English ivy & $319 \pm 20$ \\
\hline 15 & Araliaceae & Polyscias fruticosa (L.) Harms & Ming aralia & $477 \pm 26$ \\
\hline 16 & Asclepiadaceae & Hoya carnosa (L.f.) 'Variegata' & Variegated wax plant & $452 \pm 51$ \\
\hline 17 & Bromeliaceae & Guzmania sp. & Guzmani bormeliad & $535 \pm 78$ \\
\hline 23 & Marantaceae & Calathea roseopicta (Linden) Regal & Peacock plant & $650 \pm 78$ \\
\hline 24 & Marantaceae & Maranta leuconeura E. Morren & Prayer plant & $574 \pm 13$ \\
\hline 25 & Moraceae & Ficus benjamina $\mathrm{L}$. & Weeping fig & $482 \pm 36$ \\
\hline 26 & Moraceae & Ficus elastica Roxb. Rubra & Red rubber tree & $562 \pm 34$ \\
\hline 27 & Palmae & Howea belmoreana (C. Moore \& F. Muell.) Becc. & Sentry palm & $769 \pm 108$ \\
\hline 28 & Piperaceae & Peperomia clusiifolia (Jacq.) Hook. 'Variegata' & Variegated red-edged peperomia & $935 \pm 22$ \\
\hline
\end{tabular}

Data are means \pm SEM $(\mathrm{n}=3)$.

${ }^{\mathrm{z} S y n}$. Diffenbachia amoena Hort. and Bull.

${ }^{\text {y }}$ Syn. Scindapsus aureus Engl.

${ }^{x}$ Syn. Dizygotheca elegantissima (Veitch) R.Vig. and Guillaumin.

gaskets in which a 4.2-mm-thick EPDM rubber gasket was sealed within a Teflon envelope (Phelps Industrial Products, Elkridge, MD). The inlet port was connected to a charcoal filter [Pyrex glass tube $(10 \mathrm{~cm} \times 1 \mathrm{~cm}$ i.d. $)$ with $2.5 \mathrm{~g}$ of charcoal (Alltech Assoc. Inc., Deerfield, IL)] such that purified air was introduced into the jar at $150 \mathrm{ml} \cdot \mathrm{min}^{-1}$. The plants were placed in the jars $24 \mathrm{~h}$ before treatment and were maintained at $\approx 5.45 \mu \mathrm{mol} \cdot \mathrm{m}^{-2} \cdot \mathrm{s}^{-1} P A R$ during a light period $(12 \mathrm{~h})$. Just before the introduction of the VOCs, the inlet and outlet ports were closed using gas-tight Swagelok fittings (Georgia Valve \& Fitting, Co., Alpharetta, GA). The exit port was configured with Swagelok fittings holding a gas-tight gas chromatography septum that was capped to prevent leakage. The cap was briefly removed when a gas sample was drawn for analysis. The individual plants were exposed to $\approx 10$ ppm $\left(31.9,53.7,37.7,46.7\right.$, and $\left.55.7 \mathrm{mg} \cdot \mathrm{m}^{-3}\right)$ of high-purity analytical-grade benzene, TCE, toluene, octane, and $\alpha$-pinene (Table 2), respectively, in the gas-tight glass jars. Through preliminary tests, concentrations of 9.66 (30.9), 11.00 (59.1), 9.66 (36.4), 9.49

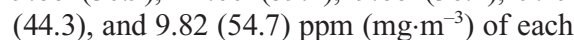
compound were created by introducing 2.0 , 2.7, 2.4, 4.0, and $4.0 \mu \mathrm{L}$ of benzene, TCE, toluene, octane, and $\alpha$-pinene, respectively, into the jar using a microsyringe (Agilent Technologies, Wilmington, DE) and calibrating the amount of each compound adsorbed onto the inner surface of the jar. A small $4 \mathrm{~cm}$ diameter 6-V DC brushless fan (RadioShack, Fort Worth, TX) was placed near the top of each jar to ensure adequate mixing of the volatiles. The gas concentration within the jar was determined after 3 and $6 \mathrm{~h}$ during the day. Three replications of each species were tested at a setting with a fourth jar used as a control without the potted plant to measure the concentration of airborne VOCs within the empty jar. Leak tests were carried out on the empty jar before every fourth experiment; no leakage was found during the 6-h test period.

Analysis of volatile organic compounds. Air samples $(1.0 \mathrm{~mL})$ within the glass containers were removed during the light period from the outlet port using a gas-tight syringe (Agilent Technologies) 3 and $6 \mathrm{~h}$ after exposure to the test VOCs and analyzed by capillary gas chromatography-mass spectroscopy (GC-MS) (6890N/5973; Agilent, Palo Alto, CA) equipped with a $30 \mathrm{~m}$ length $(0.25 \mathrm{~mm}$ i.d., $0.25 \mu \mathrm{m}$ film thickness of $5 \%$ phenyl methyl siloxane) capillary column (HP-5MS; Agilent). The injection port temperature was $225^{\circ} \mathrm{C}$ and was operated in the splitless mode. Helium was used as the carrier gas at a flow rate of $1.8 \mathrm{~mL} \cdot \mathrm{min}^{-1}$. The column temperature was held at $36{ }^{\circ} \mathrm{C}$ for $0.5 \mathrm{~min}$ and then programmed at $10{ }^{\circ} \mathrm{C} /$ min to $90{ }^{\circ} \mathrm{C}$ and held for $1 \mathrm{~min}$. Mass spectroscopy conditions were: ion source $230{ }^{\circ} \mathrm{C}$; electron energy $70 \mathrm{eV}$; multiplier voltage $1247 \mathrm{~V}$; GC-MS interface zone 280 ${ }^{\circ} \mathrm{C}$; and a scan range of 35 to 350 mass units. For quantifying absolute concentrations of each compound, standard curves for each compound were determined using analytical standards. Solutions of $0.5,1,2,5,10,20,50$, and $100 \mu \mathrm{L} \cdot \mathrm{L}^{-1}$ in hexane of each compound were prepared. Each standard solution (1.0 $\mu \mathrm{L}$, three replications) was injected directly into the GC-MS using a microsyringe. The concentration of VOCs removed by a plant was calculated as (Yoo et al., 2006):

\section{(A) VOC removal efficiency}

$$
=[\mathrm{C}-(\mathrm{S}-\mathrm{M})] /(\mathrm{L} \times \mathrm{T})
$$

(B) Accumulated removal concentration of

$$
\mathrm{VOC}=[\mathrm{C}-(\mathrm{S}-\mathrm{M})] / \mathrm{L}
$$

where:

$$
\begin{aligned}
\mathrm{C}= & \text { the concentration of VOC in the } \\
& \text { control jar }\left(\mu \mathrm{g} \cdot \mathrm{m}^{-3}\right) \\
\mathrm{S}= & \text { the concentration of VOC in the } \\
& \text { sample jar }\left(\mu \mathrm{g} \cdot \mathrm{m}^{-3}\right)
\end{aligned}
$$

Table 2. Accumulated removal concentration of volatile organic compounds (VOCs) by plastic pot $(10 \mathrm{~cm}, 500 \mathrm{cc})$ containing soilless media without plant $3 \mathrm{~h}$ and $6 \mathrm{~h}$ after introduction of five representative VOCs [benzene, toluene, octane, trichloroethylene (TCE), and $\alpha$-pinene].

\begin{tabular}{lcc}
\hline & $\begin{array}{c}\text { Accumulated removal concn by plastic } \\
\text { pot containing media }\left(\mu \mathrm{g} \cdot \mathrm{m}^{-3}\right)\end{array}$ \\
\cline { 2 - 3 } VOC & $3 \mathrm{~h}$ & $6 \mathrm{~h}$ \\
\hline Benzene & $0.34 \pm 0.06$ & $0.38 \pm 0.05$ \\
Toluene & $1.13 \pm 0.06$ & $1.21 \pm 0.04$ \\
Octane & $0.35 \pm 0.08$ & $0.47 \pm 0.07$ \\
TCE & $1.00 \pm 0.17$ & $1.10 \pm 0.08$ \\
$\alpha$-Pinene & $1.03 \pm 0.17$ & $1.13 \pm 0.07$ \\
\hline
\end{tabular}

Data are means $\pm \operatorname{SEM}(n=3)$. 
$\mathrm{M}=$ the concentration of $\mathrm{VOC}$ in the jar containing only the plastic pot and media $\left(\mu \mathrm{g} \cdot \mathrm{m}^{-3}\right)$ (Table 2$)$

$\mathrm{L}=$ total leaf area $\left(\mathrm{m}^{2}\right)$

$\mathrm{T}=$ VOC exposure time (h)

Statistical analysis. Analysis of variance and Duncan's multiple range test were carried out by using the SAS system for Windows v8 (SAS Institute, Cary, NC).

\section{Results and Discussion}

The initial concentrations of benzene, toluene, octane, TCE, and $\alpha$-pinene within the container were $9.66 \pm 0.03$ (30.9), $9.66 \pm$ 0.07 (59.1), $9.49 \pm 0.06$ (36.4), $11.00 \pm 0.07$ (44.3), and $9.82 \pm 0.20(54.7) \mathrm{ppm}\left(\mathrm{mg} \cdot \mathrm{m}^{-3}\right)$, respectively. The concentration of each VOC, after subtraction of the concentration of VOC in jars containing the pot and media without a plant (Table 2) from that in the sample jar with plant, decreased with exposure duration, indicating VOC removal by the plants (Fig. 1). Because the test plants varied in size and foliar surface area, the removal efficiency for each VOC was expressed on a leaf area basis to allow identification of species with superior removal efficiency. VOC removal represents the effect of the plant and subterranean micro-organisms associated with the plant in the potting media, the latter of which is known to be an important contributor (Wood et al., 2002).

The removal efficiency varied substantially among the species tested: benzene $\left(0.03\right.$ to $\left.5.54 \mu \mathrm{g} \cdot \mathrm{m}^{-3} \cdot \mathrm{m}^{-2} \cdot \mathrm{h}^{-1}\right)$, toluene $(1.54$ to 9.63$)$, octane ( 0 to 5.58$)$, TCE (1.48 to $11.08), \alpha$-pinene $(2.33$ to 12.21$)$, and total VOC (5.55 to 44.04) (Table 3 ). The results demonstrate the rate of removal varies depending on the VOC in question and the plant species present.

Benzene. Six species with superior benzene removal efficiency were identified: Hemigraphis alternata $\left(5.54 \mu \mathrm{g} \cdot \mathrm{m}^{-3} \cdot \mathrm{m}^{-2} \cdot \mathrm{h}^{-1}\right)$, Tradescantia pallida (3.86), Hedera helix (3.63), Fittonia argyroneura (2.74), Asparagus densiflorus (2.65), and Hoya carnosa (2.21) (Table 3; Fig. 1A). H. alternata had the highest removal efficiency and the highest accumulated removal of benzene at $3 \mathrm{~h}$ and $6 \mathrm{~h}$. At $3 \mathrm{~h}$, five species classified as having high removal efficiency were not statistically significant in their accumulated removal concentrations; however, by $6 \mathrm{~h}$, there were significant differences (Fig. 1A). Sansevieria trifasciata (1.76), Ficus benjamina (1.66), Polyscias fruticosa (1.53), Guzmania sp. (1.46), Anthurium andreanum (1.31), and Peperomia clusiifolia (1.20) were classified as having an intermediate benzene removal efficiency; the remainder had very low benzene removal efficiencies (Table 3).

Toluene. H. alternata had the highest toluene removal efficiency $\left(9.63 \mu \mathrm{g} \cdot \mathrm{m}^{-3} \cdot \mathrm{m}^{-2} \cdot \mathrm{h}^{-1}\right)$ followed by T. pallida (9.10), H. helix (8.25), A. densiflorus (7.44), H. carnosa (5.81), F. argyroneura (5.09), and $F$. benjamina (5.06) (Table 3; Fig. 1B). The plants were much
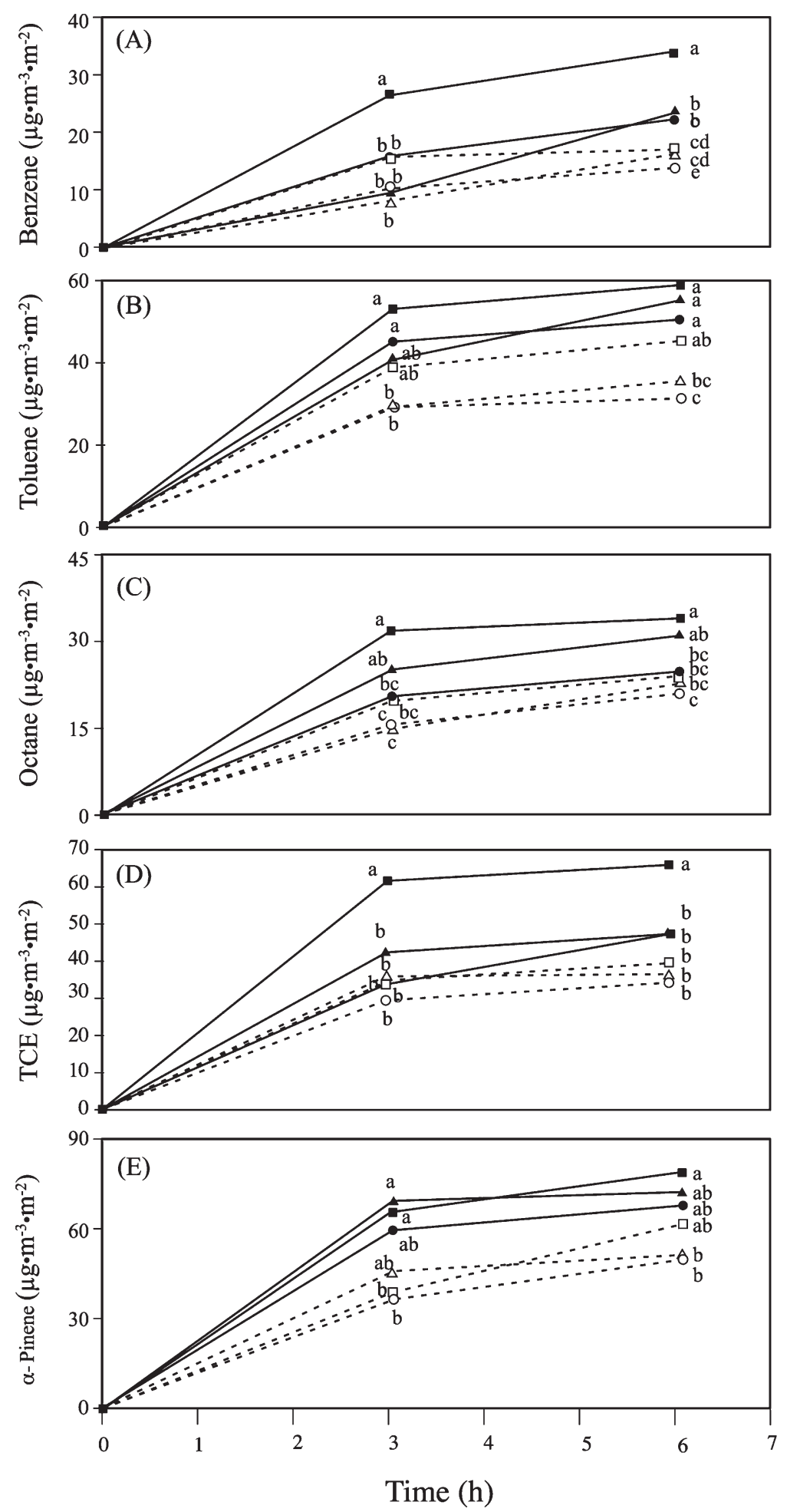

Fig. 1. Accumulated removal of $(\mathbf{A})$ benzene, $(\mathbf{B})$ toluene, $(\mathbf{C})$ octane, $(\mathbf{D})$ trichloroethylene, and $(\mathbf{E})$ $\alpha$-pinene by plants with superior volatile organic compound removal efficiency over $6 \mathrm{~h}$ during the day. Plots with different letters at the same time are significantly different by Duncan's multiple range test $(P<0.05)$. The solid squares, solid triangles, solid circles, open squares, open triangles, and open circles represent the following species in sequence: (A) Hemigraphis alternata, Tradescantia pallida, Hedera helix, Fittonia argyroneura, Asparagus densiflorus, and Hoya carnosa; (B) H. alternata, T. pallida, H. helix, A. densiflorus, $H$. carnosa, and $F$. argyroneura; (C) H. alternata, H. helix, Ficus benjamina, H. carnosa, A. densiflorus, and Polyscias fruticosa; (D) H. alternata, H. helix, T. pallida, A. densiflorus, F. argyroneura, and H. carnosa; and (E) H. helix, H. alternata, A. densiflorus, T. pallida, $F$. benjamina, and $H$. carnosa.

more effective in removing toluene than benzene, a finding corroborated by Yoo et al. (2006). The rate of toluene removal during the initial 3-h exposure was more rapid compared with the second $3 \mathrm{~h}$ of exposure. Toluene removal occurs through adsorption to the plant 
Table 3. Removal efficiency based on leaf area of five representative volatile organic compounds (VOCs) [benzene, toluene, octane, trichloroethylene (TCE), and $\alpha$-pinene] of 28 indoor plants over $6 \mathrm{~h}$ during the day.

\begin{tabular}{|c|c|c|c|c|c|c|}
\hline \multirow[b]{2}{*}{ Plant } & \multicolumn{6}{|c|}{ VOC removal efficiency $\left(\mu \mathrm{g} \cdot \mathrm{m}^{-3} \cdot \mathrm{m}^{-2} \cdot \mathrm{h}^{-1}\right)$} \\
\hline & Benzene & Toluene & Octane & TCE & $\alpha$-Pinene & Total \\
\hline \multicolumn{7}{|l|}{ Superior removal efficiency } \\
\hline Hemigraphis alternata & $5.54 \pm 0.29$ & $9.63 \pm 0.94$ & $5.58 \pm 0.68$ & $11.08 \pm 0.99$ & $12.21 \pm 1.61$ & $44.04 \pm 2.98$ \\
\hline Hedera helix & $3.63 \pm 0.33$ & $8.25 \pm 0.64$ & $5.10 \pm 0.49$ & $8.07 \pm 0.77$ & $13.28 \pm 0.95$ & $38.33 \pm 3.17$ \\
\hline Tradescantia pallida & $3.86 \pm 0.58$ & $9.10 \pm 1.17$ & $2.76 \pm 1.08$ & $7.95 \pm 1.20$ & $10.45 \pm 1.78$ & $34.12 \pm 5.52$ \\
\hline Asparagus densiflorus & $2.65 \pm 0.24$ & $7.44 \pm 0.28$ & $3.76 \pm 0.64$ & $6.69 \pm 0.49$ & $11.40 \pm 0.78$ & $31.94 \pm 2.40$ \\
\hline Hoya carnosa & $2.21 \pm 0.21$ & $5.81 \pm 0.67$ & $3.80 \pm 0.62$ & $5.79 \pm 0.75$ & $8.48 \pm 1.17$ & $26.08 \pm 3.40$ \\
\hline \multicolumn{7}{|l|}{ Intermediate removal efficiency } \\
\hline Ficus benjamina & $1.66 \pm 0.07$ & $5.06 \pm 0.19$ & $3.98 \pm 0.19$ & $4.74 \pm 0.15$ & $8.68 \pm 0.40$ & $24.13 \pm 0.86$ \\
\hline Polyscias fruticosa & $1.53 \pm 0.08$ & $4.29 \pm 0.04$ & $3.43 \pm 0.08$ & $3.98 \pm 0.16$ & $8.30 \pm 0.12$ & $21.53 \pm 0.42$ \\
\hline Fittonia argyroneura & $2.74 \pm 0.28$ & $5.09 \pm 0.23$ & $1.77 \pm 0.25$ & $6.15 \pm 0.36$ & $4.30 \pm 0.39$ & $20.05 \pm 1.46$ \\
\hline Sansevieria trifasciata & $1.76 \pm 0.48$ & $4.97 \pm 0.70$ & $2.73 \pm 0.50$ & $4.61 \pm 0.81$ & $5.49 \pm 1.31$ & $19.56 \pm 3.68$ \\
\hline Guzmania sp. & $1.46 \pm 0.25$ & $4.04 \pm 0.56$ & $2.07 \pm 0.24$ & $4.01 \pm 0.49$ & $6.43 \pm 0.55$ & $18.01 \pm 1.77$ \\
\hline Anthurium andreanum & $1.31 \pm 0.12$ & $3.60 \pm 0.37$ & $2.45 \pm 0.24$ & $3.58 \pm 0.35$ & $5.85 \pm 0.54$ & $16.78 \pm 1.59$ \\
\hline Schefflera elegantissima ${ }^{\mathrm{z}}$ & $0.66 \pm 0.19$ & $4.94 \pm 0.37$ & $0.65 \pm 0.46$ & $3.87 \pm 0.10$ & $7.33 \pm 0.36$ & $17.46 \pm 0.81$ \\
\hline \multicolumn{7}{|l|}{ Poor removal efficiency } \\
\hline Peperomia clusiifolia & $1.20 \pm 0.10$ & $2.75 \pm 0.11$ & $2.03 \pm 0.01$ & $2.40 \pm 0.13$ & $4.61 \pm 0.14$ & $12.98 \pm 0.39$ \\
\hline Chlorophytum comosum & $0.75 \pm 0.11$ & $3.18 \pm 0.14$ & $1.70 \pm 0.08$ & $2.86 \pm 0.13$ & $4.17 \pm 0.21$ & $12.66 \pm 0.54$ \\
\hline Howea belmoreana & $0.80 \pm 0.10$ & $2.95 \pm 0.32$ & $1.81 \pm 0.28$ & $2.71 \pm 0.28$ & $4.25 \pm 0.67$ & $12.52 \pm 1.64$ \\
\hline Spathiphyllum wallisii & $0.75 \pm 0.11$ & $2.52 \pm 0.13$ & $1.55 \pm 0.21$ & $2.25 \pm 0.19$ & $4.09 \pm 0.21$ & $11.15 \pm 0.83$ \\
\hline Schefflera arboricola & $0.44 \pm 0.07$ & $2.25 \pm 0.23$ & $1.75 \pm 0.13$ & $1.78 \pm 0.17$ & $4.18 \pm 0.34$ & $10.40 \pm 0.84$ \\
\hline Codiaeum variegatum & $0.89 \pm 0.04$ & $2.28 \pm 0.08$ & $1.21 \pm 0.03$ & $2.34 \pm 0.10$ & $3.61 \pm 0.09$ & $10.33 \pm 0.31$ \\
\hline Calathea roseopicta & $0.94 \pm 0.18$ & $2.70 \pm 0.38$ & $0.83 \pm 0.14$ & $2.32 \pm 0.40$ & $3.25 \pm 0.58$ & $10.04 \pm 1.62$ \\
\hline Aspidistra elatior & $0.53 \pm 0.08$ & $2.22 \pm 0.24$ & $1.22 \pm 0.17$ & $2.00 \pm 0.20$ & $3.17 \pm 0.40$ & $9.14 \pm 1.06$ \\
\hline Maranta leuconeura & $0.74 \pm 0.19$ & $2.67 \pm 0.28$ & $0.51 \pm 0.19$ & $2.35 \pm 0.40$ & $2.76 \pm 0.67$ & $9.03 \pm 1.68$ \\
\hline Dracaena fragrans & $0.55 \pm 0.01$ & $2.01 \pm 0.08$ & $1.18 \pm 0.08$ & $1.90 \pm 0.09$ & $3.31 \pm 0.19$ & $8.95 \pm 0.44$ \\
\hline Ficus elastica & $0.38 \pm 0.07$ & $2.29 \pm 0.11$ & $1.20 \pm 0.13$ & $1.75 \pm 0.19$ & $2.66 \pm 0.12$ & $8.28 \pm 0.56$ \\
\hline Dieffenbachia seguine ${ }^{\mathrm{y}}$ & $0.18 \pm 0.04$ & $2.03 \pm 0.10$ & $1.01 \pm 0.10$ & $1.83 \pm 0.07$ & $2.99 \pm 0.20$ & $8.05 \pm 0.39$ \\
\hline Philodendron scandens ssp. oxycardium & $0.49 \pm 0.08$ & $1.80 \pm 0.11$ & $0.98 \pm 0.06$ & $1.66 \pm 0.16$ & $2.33 \pm 0.12$ & $7.26 \pm 0.52$ \\
\hline Syngonium podophyllum & $0.03 \pm 0.02$ & $1.84 \pm 0.15$ & $0.76 \pm 0.16$ & $1.67 \pm 0.22$ & $2.75 \pm 0.17$ & $7.04 \pm 0.70$ \\
\hline Epipremnum aureum ${ }^{\mathrm{x}}$ & $0.44 \pm 0.05$ & $1.54 \pm 0.15$ & $0.86 \pm 0.09$ & $1.52 \pm 0.16$ & $2.34 \pm 0.21$ & $6.71 \pm 0.64$ \\
\hline Pelargonium graveolens & $0.03 \pm 0.02$ & $1.67 \pm 0.29$ & $0.00 \pm 0.00$ & $1.48 \pm 0.44$ & $2.37 \pm 0.26$ & $5.55 \pm 0.99$ \\
\hline
\end{tabular}

Data are means \pm SEM $(\mathrm{n}=3)$.

${ }^{z}$ Syn. Dizygotheca elegantissima (Veitch) R.Vig. and Guillaumin.

${ }^{y}$ Syn. Diffenbachia amoena Hort. and Bull.

${ }^{\mathrm{x}}$ Syn. Scindapsus aureus Engl. f.

surface and absorption through stomatal uptake; the removal rate depends on the number of stomata and the cuticular structure (Jen et al., 1995; Ugrekhelidze et al., 1997).

Octane. H. alternata had the highest octane removal efficiency $\left(5.58 \mu \mathrm{g} \cdot \mathrm{m}^{-3} \cdot \mathrm{m}^{-2} \cdot \mathrm{h}^{-1}\right)$ followed by H. helix (5.10), F. benjamina (3.98), H. carnosa (3.80), A. densiflorus (3.76), and P. fruticosa (3.43) (Table 3; Fig. 1C). Pelargonium graveolens had no effect on octane concentration, whereas Maranta leuconeura $\left(0.51 \mu \mathrm{g} \cdot \mathrm{m}^{-3} \cdot \mathrm{m}^{-2} \cdot \mathrm{h}^{-1}\right)$, Schefflera elegantissima (0.65), Syngonium podophyllum (0.76), Calathea roseopicta (0.83), and Epipremnum aureum (0.86) had very low octane removal efficiencies. The removal of octane, an aliphatic hydrocarbon, by indoor plants has not been reported; however, hexane, also an aliphatic hydrocarbon, was removed by Dracaena deremensis and Spathiphyllum wallisii (Wood et al., 2002).

Trichloroethylene. The six species that effectively removed toluene also had superior TCE removal efficiencies: H. alternata (11.08 $\left.\mu \mathrm{g} \cdot \mathrm{m}^{-3} \cdot \mathrm{m}^{-2} \cdot \mathrm{h}^{-1}\right), H$. helix (8.07), T. pallida (7.95), A. densiflorus (6.69), F. argyroneura (6.15), and H. carnosa (5.79) (Table 3; Fig. 1D). Similar to toluene, the highest rate of TCE removal was during the initial 3 $\mathrm{h}$, declining subsequently with the exception of $T$. pallida in which the rate remained fairly consistent. Chlorophytum comosum, which was previously reported to remove TCE
(Cornejo et al., 1999), had an intermediate TCE removal efficiency $\left(2.86 \mu \mathrm{g} \cdot \mathrm{m}^{-3} \cdot \mathrm{m}^{-2} \cdot \mathrm{h}^{-1}\right)$.

$\alpha$-Pinene. $H$. helix had the highest $\alpha$-pinene removal efficiency $\left(13.28 \mu \mathrm{g} \cdot \mathrm{m}^{-3} \cdot \mathrm{m}^{-2} \cdot \mathrm{h}^{-1}\right)$ of the 28 species tested followed by $H$. alternata (12.21), A. densiflorus (11.40), T. pallida (10.45), F. benjamina (8.68), H. carnosa (8.48), and P. fruticosa (8.30) (Table 3; Fig. $1 \mathrm{E})$.

Based on the total VOC removal efficiency, the plants were classified into superior, intermediate, and poor categories (Table 3). Five species (i.e., H. alternata, H. helix, $T$. pallida, A. densiflorus, and $H$. carnosa) with superior phytoremediation potential were identified. Their total VOC removal ranged from 26.08 to $44.04 \mu \mathrm{g} \cdot \mathrm{m}^{-3} \cdot \mathrm{m}^{-2} \cdot \mathrm{h}^{-1}$ and they effectively removed each of the test compounds. In contrast, the total VOC removal efficiency of the six plants classified as having an intermediate phytoremediation potential ranged from 17.46 to $24.13 \mu \mathrm{g} \cdot \mathrm{m}^{-3} \cdot \mathrm{m}^{-2} \cdot \mathrm{h}^{-1}$, whereas those with poor efficiencies ranged from 5.55 to $12.98 \mu \mathrm{g} \cdot \mathrm{m}^{-3} \cdot \mathrm{m}^{-2} \cdot \mathrm{h}^{-1}$.

There were no discernible trends in VOC removal potential based on taxonomical relatedness. However, the Araceae family [e.g., E. aureum $\left(6.71 \mu \mathrm{g} \cdot \mathrm{m}^{-3} \cdot \mathrm{m}^{-2} \cdot \mathrm{h}^{-1}\right), S$. podophyllum (7.04), P. scandens ssp. oxycardium (7.26), Dieffencachia seguine (8.05), S. wallisii (11.15)] generally had poor phytoremediation potential, whereas representatives of the Araliaceae family had, in general, a far better removal potential [e.g., H. helix $\left(38.33 \mu \mathrm{g} \cdot \mathrm{m}^{-3} \cdot \mathrm{m}^{-2} \cdot \mathrm{h}^{-1}\right), P$. fruticosa (21.53), and S. elegantissima (17.46)].

The volatiles tested in this study are commonly found in buildings. They can adversely affect indoor air quality and have a potential to seriously compromise the health of exposed individuals (Mitchell et al., 2007; Suh et al., 2000; Zabiegała, 2006). Benzene and toluene are known to originate from petroleum-based indoor coatings, cleaning solutions, plastics, environmental tobacco smoke, and exterior exhaust fumes emanating into the building; octane from paint, adhesives, and building materials; TCE from tap water, cleaning agents, insecticides, and plastic products; and $\alpha$-pinene from synthetic paints and odorants. Some of the common indoor VOCs are known carcinogens (Jones, 1999; Newman et al., 1997) and at sufficiently high concentrations, a number of VOCs are harmful to plants (Cape, 2003). Visible injury to plants in this study was not observed.

Although a diverse cross-section of plants was capable of removing the VOCs tested (Table 3), removal efficiency varied within a single species as a result of differences in the chemical properties of the individual compounds (e.g., polarity, vapor pressure, molecular weight, solubility, dissociation), an effect previously noted by $\mathrm{Yoo}$ et al. (2006). The fate of VOCs (e.g., accumulation, 
adsorption, absorption, penetration, transportation, metabolism), therefore, depends on the chemical characteristics of each volatile (Cape, 2003; Deinum et al., 1995; Korte et al., 2000) and the physical and chemical characteristics of the plants. Lipophilic compounds more readily penetrate the cuticular surface of plants, expediting uptake in contrast to compounds that are largely restricted to stomatal penetration (Deinum et al., 1995; Schmitz et al., 2000). In addition, the ability to metabolize VOCs varies widely among species and volatiles (Beattie and Seibel, 2007; Cape, 2003; Deinum et al., 1995; Jen et al., 1995). Therefore, a better understanding of the basic physical and chemical factors modulating the phytoremediation processes in the most efficient species is needed.

\section{Conclusions and Summary}

Of the 28 species tested, $H$. alternata, $H$. helix, H. carnosa, and A. densiflorus had superior removal efficiencies for each of the test compounds (i.e., benzene, toluene, octane, TCE, and $\alpha$-pinene). Likewise, $T$. pallida had superior removal efficiencies for four of the compounds (i.e., benzene, toluene, TCE, and $\alpha$-pinene). H. alternata, in particular, had the highest removal efficiency for four of the compounds (benzene, toluene, octane, and TCE). Indoor plants are known to confer significant psychological and physical benefits to individuals living/working in environments where they are present [e.g., reduced stress, increased task performance, and decreased symptoms of ill health (Bringslimark et al., 2007; Son, 2004)]. Based on this and other studies, plants also have the potential to significantly improve the quality of indoor air. Their increased use in both "green" and traditional buildings could have a tremendous positive impact on the ornamental industry by increasing customer demand and volume of sales. Further studies focusing on screening additional plant species for superior VOC removal efficiencies are warranted.

\section{Literature Cited}

Beattie, G.A. and J.R. Seibel. 2007. Uptake and localization of gaseous phenol and $p$-cresol in plant leaves. Chemosphere 68:528-536.

Bringslimark, T., T. Hartig, and G.G. Patil. 2007. Psychological benefits of indoor plants in workplaces: Putting experimental results into context. HortScience 42:581-587.

Cape, J.N. 2003. Effects of airborne volatile organic compounds on plants. Environ. Pollut. 122:145-157.

Cohen, Y. 1996. Volatile organic compounds in the environment: A multimedia perspective, p. $7-$ 32. In: Wang, W., J. Schnoor, and J. Doi (eds.) Volatile organic compounds in the environment. ASTM STP 1261. American Society for Testing and Materials, West Conshohocken, PA.

Cornejo, J.J., F.G. Munoz, C.Y. Ma, and A.J. Stewart. 1999. Studies on the decontamination of air by plants. Ecotoxicol. 8:311-320.

Darlington, A., M. Chan, D. Malloch, C. Pilger, and M.A. Dixon. 2000. The biofiltration of indoor air: Implications for air quality. Indoor Air 10:39-46.

Deinum, G., A.C. Baart, D.J. Bakker, J.H. Duyzer, and K. Dick Van Den Hout. 1995. The influence of uptake by leaves on atmospheric deposition of vapor-phase organics. Atmos. Environ. 29:997-1005.

Destaillats, H., R.L. Maddalena, B.C. Singer, A.T. Hodgson, and T.E. McKone. 2008. Indoor pollutants emitted by office equipment: A review of reported data and information needs. Atmos. Environ. 42:1371-1388.

Ingrosso, G. 2002. Free radical chemistry and its concern with indoor air quality: An open problem. Microchem. J. 73:221-236.

Jen, M.S., A.M. Hoylman, N.T. Edwards, and B.T Walton. 1995. Experimental method to measure gaseous uptake of ${ }^{14} \mathrm{C}$-toluene by foliage. Environ. Exp. Bot. 35:389-398.

Jenkins, P.L., T.J. Phillips, E.J. Mulberg, and S.P. Hui. 1992. Activity patterns of CaliforniansUse of and proximity to indoor pollutant sources. Atmos. Environ. 26:2141-2148.

Jones, A.P. 1999. Indoor air quality and health. Atmos. Environ. 33:4535-4564.

Korte, F., G. Kvesitadze, D. Ugrekhelidze, M Gordeziani, G. Khatisashvili, O. Buadze, G. Zaalishvili, and F. Coulston. 2000. Organic toxicants and plants. Ecotoxicol. Environ. Saf. 47:1-26.

Liu, Y.J., Y.J. Mu, Y.G. Zhu, H. Ding, and N.C. Arens. 2007. Which ornamental plant species effectively remove benzene from indoor air? Atmos. Environ. 41:650-654.

Maroni, M., B. Seifert, and T. Lindvall. 1995. Indoor air quality: A comprehensive reference book. Elsevier, Amsterdam, The Netherlands.

Mitchell, C.S., J.F.J. Zhang, T. Sigsgaard, M. Jantunen, P.J. Lioy, R. Samson, and M.H. Karol. 2007. Current state of the science: Health effects and indoor environmental quality. Environ. Health Perspect. 115:958-964.

Newman, L.A., S.E. Strand, N. Choe, J. Duffy, G. Ekuan, M. Ruszaj, B.B. Shurtleff, J. Wilmoth,
P. Heilman, and M.P. Gordon. 1997. Uptake and biotransformation of trichloroethylene by hybrid poplars. Environ. Sci. Technol. 31:10621067.

Orwell, R.L., R.A. Wood, M.D. Burchett, J. Tarran, and F. Torpy. 2006. The potted-plant microcosm substantially reduces indoor air VOC pollution: II. Laboratory study. Water Air Soil Pollut. 177:59-80.

Orwell, R.L., R.L. Wood, J. Tarran, F. Torpy, and M.D. Burchett. 2004. Removal of benzene by the indoor plant/substrate microcosm and implications for air quality. Water Air Soil Pollut. 157:193-207.

Sandhu, A., L.J. Halverson, and G.A. Beattie. 2007. Bacterial degradation of airborne phenol in the phyllosphere. Environ. Microbiol. 9: 383-392.

Schmitz, H., U. Hilgers, and M. Weidner. 2000 Assimilation and metabolism of formaldehyde by leaves appear unlikely to be of value for indoor air purification. New Phytol. 147:307315.

Snyder, S.D. 1990. Building interior, plants and automation. Prentice Hall, Englewood Cliffs, NJ.

Son, K.-C. 2004. Indoor plants help people stay healthy. Joongang Life Pub. Co, Seoul, Korea.

Suh, H.H., T. Bahadori, J. Vallarino, and J.D. Spengler. 2000. Criteria air pollutants and toxic air pollutants. Environ. Health Perspect. 108:625-633.

Ugrekhelidze, D., F. Korte, and G. Kvesitadze. 1997. Uptake and transformation of benzene and toluene by plant leaves. Ecotoxicol. Environ. Saf. 37:24-29.

Wolkoff, P. and G.D. Nielsen. 2001. Organic compounds in indoor air-Their relevance for perceived indoor air quality? Atmos. Environ. 35:4407-4417.

Wolverton, B.C., A. Johnson, and K. Bounds. 1989. Interior landscape plants for indoor air pollution abatement. Final Rept. NASA, Stennis Space Center, Mississippi.

Won, D., E. Lusztyk, and C.Y. Shaw. 2005. Target VOC list. Final Rept., National Research Council Canada.

Wood, A., R.L. Orwell, J. Tarran, F. Torry, and M. Burchett. 2002. Potted-plant/growth media interactions and capacities for removal of volatiles from indoor air. J. Hort. Sci. Biotechnol. 77:120-129.

Yoo, M.H., Y.J. Kwon, K.-C. Son, and S.J. Kays. 2006. Efficacy of indoor plants for the removal of single and mixed volatile organic pollutants and physiological effects of the volatiles on the plants. J. Amer. Soc. Hort. Sci. 131:452458.

Zabiegała, B. 2006. Organic compounds in indoor environments. Polish J. Environ. Stud. 15:383393. 